\title{
Are ABM explanations in the social sciences inevitably individualist?
}

\author{
Harold Kincaid ${ }^{1} \cdot$ Julie Zahle $^{2}$ (iD
}

Received: 15 April 2021 / Accepted: 18 October 2021 / Published online: 19 February 2022

(c) The Author(s) 2022

\begin{abstract}
Agent-based models (ABMs) are increasingly important in social science research. They have two obvious apparent virtues: they can model complex macrosociological phenomena without strong assumptions about agents and without analytic solutions for models, and they seem to instantiate the methodological individualist program in a concrete way. We argue that the latter claim is false. After providing schematic accounts of ABM models and a first introduction to ways in which to characterize individualist explanations, we work through six conceptions of individualist explanations that are decreasingly "less individualist" and argue that ABM-based explanations in the social sciences are not inevitably individualist in any of these senses. ABMs allow for explanatory relations among social entities and properties in the model environment and they are silent on what basic agents are, allowing social entities and properties to play basic explanatory roles.
\end{abstract}

Keywords Methodological individualism · Agent-based modelling · Explanation · Social sciences

\section{Introduction}

Agent-based models (ABMs) are increasingly important in social science research. They have two obvious apparent virtues: they can model complex macrosociological phenomena without strong assumptions about agents and without analytic solutions

Harold Kincaid and Julie Zahle have contributed equally to this paper.

$\bowtie \quad$ Julie Zahle

juliezahle@gmail.com

Harold Kincaid

kincaidharold592@gmail.com

1 School of Economics, University of Cape Town, Private Bag, Rondebosch 7701, South Africa

2 Department of Philosophy, University of Bergen, Postboks 7805, 5020 Bergen, Norway 
for models, and they seem to instantiate the methodological individualist (MI) program in a concrete way. This paper pursues the latter claim: Are ABM-based explanations in the social sciences inevitably individualist? Our conclusion is negative.

MI means multiple things across different contexts. On our view, discussions of MI as a general doctrine are largely unhelpful, because theses are unclear and actual implications for social science research ambiguous. There are explanatory, ontological, methodological, etc. versions of MI which have been explored in great detail in the literature (Kincaid, 1996, 1997, 2015; Udehn, 2001, 2002; Zahle \& Kincaid, 2019). Here we focus on individualism as a view about causal explanation in the social sciences, looking at debates over MI in the context of quite specific theories and modeling contexts of ABM. This allows for more nuanced and fruitful discussions of MI.

There are different ways to cash out methodological individualism as a thesis about social scientific explanation. We zoom in on two: the position that only individualist causal explanations should be offered (we call this classic MI) and the view that purely holist explanations (in which both the cause and effect are social phenomena) should always be supplemented by individualist causal explanations (this is what we shall understand by microfoundationalism). Complicating the picture further, proponents of both forms of MI may hold different views as to what an individualist explanation looks like. Our aim in this paper is not to engage in the debate about whether classic MI or microfoundationalism should be adopted (though we briefly comment on this issue in the conclusion). Nor are we concerned with the question of how individualist explanations should be circumscribed. Rather, we go over different conceptions of individualist explanations and ask relative to each conception: assuming that ABMs are used to offer potential causal explanations, are ABM explanations necessarily individualist? And as foreshadowed a second ago, we argue that this is not the case for a number of reasons.

The fact that we systematically consider numerous conceptions of what an individualist explanation amounts to sets our contribution significantly apart from earlier discussions of the relationship between MI and ABMs (e.g. Marchionni \& Ylikoski, 2013). Our approach allows us to avoid worries about basing arguments on one possible understanding of individualist explanations that defenders of the ABM-MI connection may not share (see Manzo, 2020). Moreover, as our argument strategy is to move from the "least social" or narrow versions of individualist explanations to the "most social" or inclusive versions, we are able to show that the less social (and so narrower) the versions of individualist explanations, the more reasons there are why ABM explanations need not be individualist, and that even on the most social (and so inclusive) versions of individualist explanations, there is no necessary association between MI and ABMbased explanations. We take showing that there are multiple independent reasons why $\mathrm{ABM}$ explanations are not essentially individualist to be a major contribution of the paper.

While our main target is the place of MI explanations in agent-based modeling, we think there are also implications for some important broader issues. Our analysis of the multiple specifications of individualist explanations and of the different commitments of ABMs adds to the growing literature on the importance of seeing theories, models and methodological norms as realized in their specific contexts (Morgan \& Morrison, 
1999; Sober, 1988). Our discussion is also relevant to the expanding literature on social ontology. A Quinean approach takes social ontology to be a question of what our best theories are committed to (Kincaid, 2020). Our discussion of MI and ABMs provides such an approach by detailing what sort of ontology ABMs may and may not require. Finally, the discussion that follows should generalize to uses of ABMs outside the social sciences where individualist type norms are at issue such as in ecology (Uchmanski \& Grimm, 1996).

The paper begins in Sect. 2 by outlining the details of ABMs and provides a first introduction to the different ways in which to characterize individualist explanations. Then Sect. 3 asks whether ABMs as currently instantiated lend support to the classic individualist program. Drawing on the characterization in Sect. 2, we move from the narrowest, most asocial understandings of individualist explanations to the broadest or most inclusive when it comes to admitting social factors. We find reason to doubt in each case that ABM explanations must be individualist in the specified sense. Section 4 turns to microfoundationalism which is a weaker form of methodological individualism. Also here we argue that ABM-based explanations need not be individualist in the microfoundations sense. ${ }^{1}$

\section{ABMs, models and individualist explanations}

In this section we point out the wide-spread assertions about ABMs and methodological individualism and then give schemas describing the content of ABMs and individualist explanations. The latter provides the framework for the main discussion in Sects. 3 and $4 .^{2}$

\subsection{Common assertions about ABMs and MI}

Claims that ABMs embody or at least have a close connection to MI are widespread. They are made by philosophers of social science and social scientists alike. A few example quotations will make this alleged commitment abundantly clear:

ABMs often tend strongly towards methodological individualism (O'Sullivan \& Haklay, 2000: p. 143).

Artificial societies [...] are also firmly methodologically individualist (Sawyer, 2004: p. 263).

a good many proponents of agent-based modeling explanation [...] are avowed methodological individualists (Wan, 2011: p. 188).

we $[\ldots]$ argue that ABS explanations must be regarded as explanations in terms of non-reductionist MI (Di lorio \& Chen, 2019: p. 355).

agent-based models and methodological individualism share some basic principles irrespective of the entities and levels of analysis involved by the explanatory

\footnotetext{
1 The present paper builds on Zahle \& Kincaid (2020).

${ }^{2}$ Udehn (2002) is a helpful intellectual history precursor to what we are doing here, but we are trying to develop a more explicit formalized account of different versions of individualist explanations.
} 
problem under examination. In this sense, this study claims, they are essentially linked (Manzo, 2020: p. 197).

As these claims illustrate, ABMs and the MI program are commonly associated. Our concern is with one way of spelling out the linkage, namely as the claim that ABMbased explanations are necessarily individualist.

\subsection{What are ABMs?}

The term "ABM" has somewhat different connotations over time and across disciplines. A useful first gloss comes from the early history of ABM and its influences.

ABMs got their start as it were by offering an alternative to early mathematical modeling in the social sciences such as neoclassical economics which focused on analytical results about equilibria involving idealized, noninteracting homogeneous agents. Some early models came from demography (Billari \& Praskawetz, 2003), for example. Those models were microsimulations where parameters for individual behavior were taken from real data and thus were more realistic than rational choice models, but they did not allow for interaction among agents. Schelling's (1971) work on segregation was an early pioneer that built in interactions among individuals (Squazzoni, 2000). Other early models were from the Simula programming environment (Pooley, 1987), distributed artificial intelligence (Agha, 1987), multiagent systems (Jennings et al., 1998), artificial life (Langdon, 1989), genetic programming (Holland, 1975), sociology (Epstein \& Axtell, 1996; Sakoda, 1971) ${ }^{3}$ and individual-based ecology (Uchmanski \& Grimm, 1996). Rational choice game theory was a further development helping to make heterogeneous agents possible-it allows different types of individuals with different strategies. Evolutionary game theory allowed for out of equilibrium behavior and nonrational agents, and the distinction between it and ABMs is harder to draw. Now there is significant work in political science (Laver \& Sergenti, 2012), economics (Gallegati et al., 2017; Hamill \& Gilbert, 2016), even if it still far from the mainstream, and archeology and anthropology (Kohler \& Gumerman, 2000) making use of ABMs.

Put somewhat more formally, we can think of an ABM as typically involving: (ABM1) A set I of individual agents $x 1 \ldots n$.

(ABM2) A set $\mathrm{P}$ of properties of the members of I describing their nonrelational attributes and behavior.

(ABM3) A set E of physical, biological, social, etc. environmental factors for I.

(ABM4) $A$ set $R_{i}$ of relations among members of $I$ and a set $R_{s}$ of relations among the members of $\mathrm{E}$.

(ABM5) A set of variables A recording the aggregate values of any variables in (1)-(4).

Not every ABM necessarily has all these elements. For example, less complex models may not include $\mathrm{R}_{\mathrm{s}}$.

Then with the above, an ABM involves setting the initial values of any parameters asserted and a set of rules for running the model, i.e. for doing an initial instantiation, and then subsequent runs with updated values which may include deleting and adding

\footnotetext{
3 A useful history of Schelling and Sakoda style models is Hegselmann (2017).
} 
new members of I. The "runs" involve calculating new values of variables and then running the model code again, storing values and then repeating the process. Some of the variables may be exogeneous - determined outside the model-while others are often endogenous, determined inside the model. While in principle there exists a function relating the total state of all variables from one run of the program to another, a full knowledge of the model at the initial state does not mean we can know a function that determines the next total state of the model. In this sense- the lack of deducibility or predictability_ABMs produce "emergent" results, what Bedau (1997) calls "weak emergence." Also, while probably most ABM modelers think of the changes over model state spaces as providing causal explanations, they may also work in terms of one temporal state space "determining" another or other such notions that are not explicitly causal. We generally take ABM models as providing causal explanations, though we believe that our points presuppose no specific account of causality. We also recognize that models play many roles in science aside from explanation. Our focus here however is explanatory uses of ABMs, where the sense of explanation we have in mind is broadly providing accounts of causes.

The above elements of ABMs are widely known to ABM practitioners of course, but not necessarily to other social scientists and philosophers of science and, whatever the audience, it is useful to clarify ABMs, given the looseness with which the ABM terminology can be used. In particular and important to our purposes, we need to note that (1)-(4) can have multiple interpretations.

Elements (3) and (4) listed above can be empty and when they are not, they can have more or less rich ontologies. The variety of basic growth models in the literature have no specification for (3) and (4) at all. Evolutionary game theory inspired models sometimes only have a physical and biological environment. Other models may contain social elements of various kinds including full-fledged social entities such as formal organizations like banks and governments or less explicitly organized social structural elements such as norms, network structure, and social roles or types of individuals. Also, important for the arguments to come, the set I of basic entities makes no commitment about what kind of entities those are- the formal model is silent and has to be given an ontology when used.

Similarly, we should note that the term "agent" has an important role but varying possible meanings in different ABMs. The fundamental idea is that the basic entities of the model are "autonomous," though autonomous itself suffers similar vagueness as "agent." Yet, there is a core idea: agents are not directed from the top but instead have their own behavioral rules. The rules involved can be simple or complex. But in any case there is still supposed to be a fundamental divide between active agents and a passive environment.

It will also be helpful to clarify further the sense of "model" being used in discussions about ABMs. Of course, the term generally and in the ABM literature in particular may have multiple uses, but since individualism, as we consider it, is an explanatory thesis, we need to narrow the focus to ABM models as explanations, though models can no doubt have many other functions. One standard notion of a model is that of abstractions or simulata describing entities and relations between them that can be used to potentially explain the world. Models in this sense can run from abstract entities like sets of equations to concrete physical objects like Watson-Crick DNA models. 
For ABMs, the model objects are the agents and their traits and rules for behavior, their environment, initial values of parameters and so on-the elements of (1)-(5) given a specific interpretation for application to the phenomena to be studied. Thus, to be perhaps pedantically clear, the model is not the running of the simulation nor the reports generated about aggregate values of variables, which are items to be explained. Instead, the model involves (1) the set of statements about agents, environment, etc. at the initial iteration the values of which fix (deterministically or probabilistically) the subsequent realizations of the model after each simulation run, and (2) the surrounding framework that interprets the targets of the model-how the agents, environment, etc. are understood. Models are not just a set of equations but are abstracta embedded in a larger scientific context that determines their purpose and what they represent and how (Hesse, 1966; Morgan, 2012). The formal structure of ABMs is given an interpretation assigning entities to variables according to the intended application.

\subsection{What are individualist explanations? A basic schema}

Numerous different theses go by the label of methodological individualism. While there have been some serious attempts to sort them out (e.g. Kincaid, 1996, 1997; Udehn, 2002), usage continues to be imprecise. The core meaning that concerns us is the claim that causal explanations in the social sciences should be in terms of individuals. Thus, we put aside individualist theses about theory reduction, epistemology, and ontology. While there may be logical or other kinds of close connections to these other versions of individualism, considering the entire complex is beyond the scope of this paper. It is explanatory claims that surface consistently in debates about ABMs and MI and thus that is our concern.

Methodological individualists circumscribe individualist explanations-explanations in terms of individuals - in different ways. We will detail various conceptions of individualist explanations as we discuss ABMs. However, it will help to have a first schematic outline of individualist explanations in general. So, let

I stand for a set of individual humans

$\mathrm{P}$ stand for a set of nonrelational properties of the members of I

PHY stand for a set of factors in the physical environment, construed broadly enough to include the biological environment

$\mathrm{R}$ stand for a relation of a member of I to some other member of I

SE stand for a set of social entities, social properties, and social processes

Then consider the following set of individualist claims in order of decreasing commitment gaged in terms of how much they stick to strictly individual facts:

a. Individualist explanations only refer to I and P

b. Individualist explanations only refer to I, P, and PHY

c. Individualist explanations only refer to I, P, PHY, and R

d. Individualist explanations only refer to I, P, PHY, R and SE 
This is just a first abstract schema for clarifying individualist explanations in terms of the basic categories that they may mention. ${ }^{4}$ Crucially, the above claims leave open important questions concerning just what kind of relations between individuals count as individual or social, what social entities come to, and what kind of restrictions on individualist explanations are involved over and above mere ontology. These further details will be fleshed out as we look at specific understandings of individualist explanations in relation to ABMs. As we noted above, methodological norms generally get real content in specific applications.

To finish this discussion of individualist explanations, we want to make what we take to be an important methodological (and ultimately Quinean) point. While the above theses about individualist explanations are general, our concern will be with their adequacy as descriptions of existing ABMs as opposed to the much more intractable question about their adequacy for all (existing? possible?) social theory or explanation. We think these well-specified individualist theses in the context of specific social science research is the way forward for debates about MI.

Our discussion of ABMs and individualist explanations above make it clear both that claims about individualist explanations and ABMs have to be interpreted and leave considerable room for different content according to context and use. We turn next to examine the various ways that ABMs might be or not be consistent with MI.

\section{Are ABM-based explanations necessarily individualist in the classic sense?}

Classic methodological individualism is the position that, in the social sciences, only individualist causal explanations should be offered, that is, explanations (explanantia) which focus on how individuals brought about some event (Zahle \& Kincaid, 2019). Homans' (1974) explanations of small group behavior and Becker's (1976) explanations of discrimination completely in terms of individual motivation are well-known social science examples of MI; indeed, much of neoclassical microeconomics can be seen as seeking to explain entirely in terms of individual preferences and resources.

In light of how ABMs work as described in Sect. 2, it is easy to see that at least superficially they might provide individualist explanations: the agents in an ABM may simply be interpreted as individual human beings and the ABM then provides an explanation based on the rules governing individual behavior. The question is, however, whether social science ABMs necessarily implement the classic methodological individualist program. In other words: are social scientific explanations based on ABMs inevitably individualist? In what follows, we argue that they aren't.

Classic methodological individualism comes in different versions depending on how an individualist explanation is specified as we noted above. Most notably, there are diverse versions depending on the scope of an individualist explanation, that is, depending on the different kinds of entities they are allowed to refer to. Historically

\footnotetext{
4 We avoid trying to put these claims in more ontological terms as, for example, about properties, etc. These issues easily become complex and controversial. Our main aim is to ask the Quinean question what are ABMs committed to.
} 
speaking, proponents of methodological individualism have tended to defend increasingly broader notions of individualist explanations (Udehn, 2002: p. 498) in that the traits and entities involved are more "social" and less atomistic. At the same time, they have imposed important constraints on what explanatory roles these traits and entities are allowed to play.

Our discussion below mirrors this broad development without pretending to be historically exact (the history of the debate is much messier). We begin by considering narrow conceptions of individualist explanations and then proceed to examine progressively more inclusive ones. For each conception we show that ABM-based explanations are not necessarily individualist for that reading of individualism. The way we have set up the discussion, any reasons to think that ABM-based explanations are not necessarily individualist in a specific form equally applies to the weaker, less social notions of individualist explanations that were considered previously. As such, our discussion shows that the narrower the notion of individualist explanation, the more reasons there are why ABM-based explanations are not inevitably individualist and that even on the most inclusive understanding of an individualist explanation, current ABM-based explanations do not necessarily support the individualist program. We regard this as a main achievement of our analysis.

Marchionni and Ylikoski (2013) also argue that there is no necessary linkage between ABMs and MI, but they rely on a single notion of individualist explanations, one that is not defended by most contemporary advocates of MI. Our project is the bigger one of considering multiple conceptions of individualist explanations and demonstrating, to repeat, that there is no necessary association between ABMs and classic MI irrespective of how narrowly or broadly individualist explanations are circumscribed. ${ }^{5}$ A side effect of showing this is that we are able to bring out not only the breath of versions of methodological individualism, but also the great flexibility in the ways ABMs may provide explanations that involve individuals - a point which tends to go rather unnoticed in current philosophical discussions of ABMs. We also differ from Marchionni and Ylikoski in that they tie their arguments to a particular theory of causal explanation, whereas we want to leave it open how causal explanations (and causation) should be spelled out. Participants in the individualism-holism debate hold different views on this matter. At the same time, we believe that our arguments in the following do not presuppose (they may easily be adapted to) any specific account of causal explanations. It is exactly this point we want to get across by not relying on any particular theory of causal explanation.

There are two basic positions in the classic individualism-holism debate. One is methodological individualism; the other is methodological holism. Holism—which is, simply put, the position that either all or some causal explanations should be holist, that is, in terms of social entities and their properties - comes in various forms with different logical strength. Since our concern is with MI, we do not formulate different versions of holism, though our multiple formulations of what an individualist explanation amounts to will suggest indirectly different holist theses.

\footnotetext{
5 Marchionni and Ylikoski take MI to be the view that "[s]ocial phenomena can only be explained (or they are best explained) by accounts that only refer to individuals, their properties and interactions" (Marchionni and Ylikoski 2013: p. 332). To anticipate the six notions of MI, we introduce below, their version is consistent with our version (1) below, but not with versions (2)-(6) that are broader than their version.
} 
We now describe a series of notions of individualist explanation that run from the strongest-most individualist - to the most social. As stressed in the introduction, we are not concerned with how individualist explanations should be circumscribed, let alone with the question of whether classic methodological individualism should be espoused. Rather, our project is, to repeat, to examine whether, relative to various notions of individualist explanations, ABM explanations are necessarily individualist.

Our sequence of increasing less individualist theses is a natural way to think about some of the founding work on ABMs, e.g. Epstein's (2006) generative social science and Schelling's generative account of discrimination. This general program asked how little social information was needed to generate models of social outcomes from individual behavior. Thus, Epstein (2006) says about his study of the Anasai historical data that his simulations show that "subsistence considerations alone do not fully explain the Anasazi's departure [demographic decline], and that institutional or other cultural factors were likely involved. This works suggests the power and limits of a purely environmental account" (p. 12). The generative social science program thus can be seen as investigating which of the formulations that follow below suffice to explain social science data such as the Anasai data. It is also important to note that the "generative program" is also an attempt to do simulations that reproduce social science data, something that does not require a commitment to what levels are used in models.

We start with the strongest individualist notion:

(1) Individualist explanations are ones that only describe individuals and their nonrelational properties. ${ }^{6}$

For the present purposes, an individual's nonrelational properties may be specified as the properties she possesses independently of standing, at that moment, in certain relations with other individuals. Thus, walking, reading, and having red hair and blue eyes exemplify nonrelational properties. An individualist explanation along these lines might point to the work ethic of individuals as the cause of the prosperity of a country. Versions of what is known as atomism or psychologism sometimes illustrate this position.

If this notion of individualist explanations is adopted, then it is rather obvious that ABMs do not necessarily implement the methodological individualist program. While many ABMs, especially in their early instantiations, did in fact work in such atomistic ways, they need not. Among other things, ABMs may model individuals' physical circumstances of action such as the vegetation in their environment and the tools at their disposal. Accordingly, ABM-based explanations may also mention individuals' physical environment, but these explanations would not count as individualist for this most narrow version of MI.

\footnotetext{
6 There are numerous individualists and research programs that advance this strong version of individualist explanations or at least seem to presuppose it. In general equilibrium neoclassical models where everybody is a price taker, the no trade theorems show that a world is described where individuals do not interact. A variety of sociobiological accounts of social phenomena work by just summing the physical characteristics of individuals. Even if such examples could be shown to be differently interpretable, being explicit about the pure case of individualist explanations is important for our strategy of canvassing the logical space. The earliest, simple ABMs certainly worked in this way.
} 
At the same time, these considerations certainly have only limited force. While current critics of MI sometimes maintain that individualist explanations are not permitted to refer to individuals' physical surroundings (for instance, this view seems to underlie the discussion in Epstein, 2015), the endorsement of (1) is not widespread among contemporary methodological individualists. In fact, there is a long tradition among methodological individualists for specifying individualist explanations as including descriptions of individuals' physical context of action (see Agassi, 1960, 1975). ${ }^{7}$ (The idea of a context of action is basically the same as an exogenous variable). In light of these considerations, we next move to a broader version of individualist explanations:

(2) Individualist explanations are ones that describe only individuals, their nonrelational properties, and their relations to the physical environment that is their context of action.

"Physical" here again is construed broadly to include the biological and other aspects of the environment, though not social phenomena that the holist would want to appeal to.

It seems clear that ABM-based explanations need not be individualist in this sense. That is because (2) excludes properties relating individuals to each other. Of course, such properties are socially fundamental and ABMs can model them. Sometimes, these properties are identified with properties like "exchanging food with somebody" and "living next to somebody." Other times, they are taken more broadly to include what is standardly referred to as social role properties such as being a nurse, a politician, and teacher; and voting, firing, and hiring. For an individual to have such social roles is simply for her to stand in specific relations to other individuals (see, e.g. Hodgson, 2007: p. 220). Similarly, the performance of role actions, like firing, hiring, and voting, is seen as going hand-in-hand with an individual being related to other individuals in specific ways, e.g. one person can only fire another if they are related as employeremployee. In this fashion, social role properties are regarded as a special kind of relational properties.

For the present purposes, the exact distinction between relational properties as narrowly and broadly construed does not matter. The important point to note is that ABMs can model both relational properties of the narrow sort and role properties. An ABM may model individuals who exchange food with each other and mention this fact as part of the ABM-based explanation. ABMs also may model agents in ways that they may be interpreted as having various social roles as illustrated by Kirman and Vriend's ABM of the Marseille fish market (Kirman \& Vriend, 2001). In the explanations based on this model, the agents are described in terms of their social roles as either sellers or buyers at the fish market. Insofar as ABM-based explanations may refer to individuals' relational properties, it follows that ABMs do not necessarily implement the individualist program as represented by (2).

In the recent debate, it is mainly opponents of methodological individualism who take it that individualist explanations are not allowed to refer to any relational properties (see, e.g., Elder-Vass, 2010). At least since the 1950's, few, if any, methodological individualists have advocated this view. For instance, Watkins, a key protagonist of

\footnotetext{
7 This as well as other comments on different versions of individualist explanations draws on Zahle (2019).
} 
methodological individualism, explicitly states that individualist explanations may refer to relations between individuals (Watkins, 1957: p. 106). And in several of his papers, Watkins offers examples of individualist explanations that refer to individuals' social roles (Watkins, 1952, 1957). On a more general note, in his classic 1968 paper, Stephen Lukes observes that this inclusive view of individualist explanations is widespread among individualists (Lukes, 1968: p. 125). Nothing in the foregoing argument will convince these methodological individualists (viz. ones who permit individualist explanations to refer to individuals' relational properties) that ABM-based explanations are not necessarily individualist.

In order to accommodate individualists of this stripe, we move to an even broader specification of individualist explanations:

(3) Individualist explanations are ones that describe only individuals, their nonrelational properties, their relations to their physical environment that is their context of action and to other individuals.

While this notion of individualist explanations allows mentioning of individuals' physical circumstances of action and relations to others, the obvious problem-especially to most social scientists-is that it prohibits mentioning social entities and social properties as part of the context of action. It is hard to imagine that large parts of social science can be done without appeal to some such social elements as part of individuals' circumstances of action.

ABM modelers recognize this need and regularly invoke social entities and social properties in their models. They may model social entities, as part of individuals' environment, for example, by letting the agents in the model act in ways constrained or facilitated by social entities. For instance, state entities may enforce punishments by confiscating individual resources and so on. Similarly, an ABM may specify rules for agents that may be interpreted as codified laws and social norms. The latter are often regarded as a form of social properties and are mentioned as part of a description of individuals' context of action, that is, as laws and norms that are followed in the circumstances in which individuals find themselves. Similarly, an ABM of individuals who are either employed or unemployed may also be considered from the perspective of what the unemployment rate is within their group. Accordingly, an ABM explanation may describe individuals as acting in a social environment characterized by high unemployment — or by other macro factors like the rate of interest. ABM explanations like this are not individualist in the way (3) requires.

However, as we have already seen, individualism is a doctrine with multiple facets. There are avowed methodological individualists who are happy to mention institutions as part of individuals' context of action - this doctrine is sometimes called 'institutional individualism". In their view, institutions include social entities, like states and schools, and/or codified laws and norms (the literature is not good about keeping institutions as concrete social organizations distinct from networks of norms without explicit formalized institutions). Traditionally, explanations that refer to social institutions have been regarded as straightforward holist explanations and commonly the same has been the case with respect to explanations by appeal to codified laws and social norms. However, institutional individualists hold that insofar as institutions are only mentioned as part of a description of individuals' context of action, these 
explanations are still individualist because the focus is on individuals. Institutions only set the stage for individuals' actions; they are relegated to a secondary and passive role as part of individuals' circumstances of action. Or, as Popper describes it, institutions "set limits or create obstacles to our movements and actions almost as if they were physical bodies or obstacles" (Popper, 1996: p. 167). However, social entities and social properties in this form of individualism are not active factors. Thus, it is worth stressing, institutional individualists still count explanations as holist if these assign social institutions any other role than that of serving as the set background against which individuals act. As background, institutions are like oxygen in the case of the spark that caused the fire-the given circumstances under which the active cause works. The circumstances of course are part of the causal story, but they are not the causal agent. Insofar as methodological individualists are willing to refer to institutions as part of individuals' context of action, it is not obvious why they should oppose the description of other social factors as part of individuals' context of action. Moreover, some ABM theorists imply that methodological individualists may indeed describe other such factors. For instance, Macy and Flache maintain both that ABMs implement the methodological individualist program, and that ABMs have social properties such as network structures (Macy \& Flache, 2009). This suggests that they take methodological individualism to be compatible with the description of social properties as part of individuals' circumstances of action. For these reasons, we shall grant that methodological individualists may maintain that individualist explanations may mention whatever social entities and social properties they please as long as these are described as part of individuals' context of action. Such formulations may be unclear and normatively suspect, but our goal here is not to make such judgments but to argue that whatever formulations of individualist explanations are given, ABMs are not committed to them.

The position of institutional individualism was first sketched by Popper and subsequently elaborated by Agassi and Jarvie (Agassi, 1960, 1975; Jarvie, 1972). ${ }^{8}$ Today, institutional individualism is widely endorsed. As Lars Udehn remarks, it "is the dominating version of methodological individualism, both in political science and in the new institutional economics" (Udehn, 2001: p. 348). It is a little harder to determine how widespread the even more inclusive individualist position is (the one that allows all social entities and properties to be described as part of individuals' context of action). In any case, the preceding discussion of ABM-based explanations that refer to individuals' institutional context of action will not make institutional individualists give up on the claim that ABMs may only provide individualist explanations. And the same goes for the view that in individualist explanations any social entities and properties may be mentioned as part of individuals' context of action.

These broad conceptions of individualist explanations may be put together and summarized as follows:

(4) Individualist explanations are ones that describe only individuals, their nonrelational properties, their relations to their physical environment that is their context

\footnotetext{
${ }^{8}$ For a discussion of Popper's scattered remarks on this issue, see, e.g., Udehn (2001: p. 200ff) and, in particular, Hedström et al. (1998) and Jarvie (1998).
} 
of action, their relation to other individuals, and their relations to their social environment that is their context of action.

Now we have considerably weakened the force of individualism in the pursuit of the idea that ABMs support the individualist agenda. What remains of that program in (4)? Popper and current advocates in the analytic sociology movement still keep their individualist bonafidas because they limit the social to what we have been calling the "context of action," which is the institutional or social background. But they take the context of action to be background-something fixed against which agents act but not an active causal force in the social world. Social phenomena are part of the explanation, but their role is restricted. All the explanatory work comes from the actions of individuals in the sense that they alone are active causal agents in the social world.

We note again that the move to (4) illustrates how abstract schemas of both theories and models (ABMs) and the claims about individualist explanations sketched in Sect. 2 have to be interpreted and are open to multiple different interpretations with substantially different implications. (4) is a much weaker understanding of individualist explanations and allows for a richer ABM than (1)-(3). Referring back to our abstract schema for MI in Sect. 2, (4) is an instantiation of (d)—of "Individualist explanations only refer to I, P, PHY, R and SE." SE—-social entities, properties and processes - is interpreted in a specific way by the institutional individualist (4) as the "social context of action" where the latter refers to passive or static (Salaman, 2011, p. 22) social factors which constrain individuals' actions. This is not the only way to instantiate (d) as we will see in versions (5) and (6) of individualist explanations below.

The question is then whether ABMs have to be restricted only to what is allowed in (4). The answer is no for two reasons. First, ABMs can and often do allow for the causal interaction of social factors in the environment agents face. We see two broad circumstances where this can be the case (as we also explain below): when the characteristics of social entities have causal effects on each other and where what you might call social structural or social aggregate properties (shortly to be specified) stand in causal relations. In the abstract schema of ABMs given in Sect. 2, these would be causal relations in the sets $\mathrm{E}$ of $\mathrm{ABM} 3$ and $\mathrm{A}$ of ABM5. These can ground explanation on their own.

The use of social entities in the individual agents' environment with causal influence on each other is entirely compatible with ABMs and not an uncommon modeling strategy. To cite an example, Hamill and Gilbert (2016) develop a financial economy ABM where individuals have banks in their social environment as well as a regulatory agency. The regulatory agency influences the behavior of the banks. Individual saving decisions are made in the context of action that the banks and regulatory agency provide. Individuals make decisions about distribution of income across savings and consumption, and their decisions determine — and hence explain — the amount of deposits available and thus influence the rate at which banks loan along with the rules set by regulators. The social context of action thus may be dynamic and causally active, something not allowed by version (4) of individualist explanations. 
Social aggregate factors that are part of the context of action can likewise causally interact. Social aggregate properties, as we use the term here, are social properties that are sets of the properties of individuals and relations on those individual properties. These properties can be relatively simple as in averages (the rate of unemployment) or can be considerably more complex as there is more structure on the set as is the case of formal network properties (e.g. the structure of a network of individuals such as density, centrality, etc.). An ABM of individual agents may describe various social aggregate properties. For instance, taking the simple case, it may be that a certain proportion of the individuals have a certain property $p$. Assume that this model is run several times and that each time the proportion of individuals who have $p$ is $x$. Moreover, suppose that it appears that an increase in the proportion of individual agents with $p$ makes a difference to the result of the running of the ABM, say, the distribution of another property $q$ in the population of individual agents. In that case, a corresponding ABMbased explanation might simply state that an increase in the proportion of individuals with $p$ leads to an increase in the proportion of individuals with $q$. Examples with much more complex structured aggregate properties can easily be found, e.g. in ABMs with social network elements (Di Guilmi, 2018; Namatame \& Chen, 2016). Explanations of these sorts focus on the relation between social properties, something which (4) does not allow and hence it follows, once more, that ABM-based explanations are not necessarily individualist. ${ }^{9}$

We have argued that social factors in the individuals' environment need not be causally passive contra (4). However, there is another, perhaps deeper reason that social factors need not be so in ABMs. Let's go back to our original abstract presentation of ABMs. We said they quantified over individuals, but that was individuals in the logician's sense and had no inherent connection to individual human beings. Nothing in the ABM formalisms requires that the agents are individual human beings. As noted already above and as widely recognized in the model literature, models may be abstractions that have to be interpreted to be applied. ABMs in practice often take as their basic agents or "individuals" social entities and institutions. ${ }^{10}$ For example, numerous ABMs in economics work with firms, banks, central banks, and governments as their basic individuals. Likewise, political science ABMs sometimes take political parties as the basic individuals. Thus, ABM-based explanations need not mention any individual human beings at all. They may solely point out how social entities and institutions - as the causally active agents-brought about some effect.

This objection to MI restrictions on explanation, like all our previous objections, applies to the stronger notions of individualist explanations already discussed. It is a compelling reason to doubt that ABMs must be individualist in a nontrivial sense. However, perhaps there are individualist restrictions that ABMs must follow even

\footnotetext{
9 So the two points here are generally acknowledged in the ABM literature: "the environment is often nothing more than a special kind of agent-like entity...there can be behaviors and data stores [aggregate properties-au] in the environment" (Salaman 2011, p. 152).

10 It is interesting to note here that a natural pragmatic feature of modeling may be to focus primarily on the fundamental agents of the model for reasons of simplicity, tractability, and so on. In ABMs those agents do not have to be individual human beings, so the pragmatics pushes toward a sort of "atomism," where the explanations are in terms of fundamental entities in the model, be they individual humans or some kind of collective agents.
} 
when they model causally active social factors? We look at that prospect in the next section.

\section{Are ABM-based explanations necessarily individualist in the microfoundations sense?}

The classic methodological individualist maintains that, in the social sciences, only individualist explanations are adequate. By implication, holist explanations should be dispensed with. There is, however, a more recent form of methodological individualism commonly referred to as microfoundationalism that is characterized by a more tolerant attitude towards holist explanations. Rather than stating that holist accounts should be dispensed with, it only maintains that some types of holist causal explanations must always be supplemented by an individualist causal explanation. Since this form of individualism espouses an even broader notion of individualist explanations than proposed by (4), it is natural to wonder whether it is at least the case that ABMbased explanations are necessarily individualist in the microfoundational sense. In the following, we distinguish between two versions of microfoundationalism in terms of how inclusive a notion of individualist explanation they advocate. We argue that even on the most inclusive conception, ABM-based explanations do not inevitably implement the microfoundational thesis. As in the previous section, we do not take a stance on whether the microfoundationlist position should be adopted and how individualist explanations should be understood.

Microfoundationalism is the thesis that, in the social sciences, purely holist explanations should always be supplemented by individualist explanations. A purely holist explanation is one in which both the explanans and explanandum refer to social phenomena, that is, social entities, social processes, and social properties. ${ }^{11}$ In turn, in the context of the microfoundations debate, individualist explanations are conceived of as follows:

(5) Individualist explanations are ones that describe only individuals, their nonrelational properties, their relations to their physical environment that is their context of action, their relations to other individuals, their relations to their social environment that is their context of action, and the social phenomena that causally influence them. These descriptions are part of specifying the underlying individual-level mechanisms that link social phenomena. ${ }^{12}$

For the present purposes, "mechanisms" may simply be spelled out as causal chains of events. Moreover, that there are underlying individual-level mechanisms means,

\footnotetext{
11 Within this debate, social phenomena are commonly specified as social-level, higher-level, or macrophenomena. These can be explicit social organizations like schools and states, social factors like norms, cultures, religious practices, and so on. In order to keep the following presentation simple and in line with the foregoing discussion, we mainly talk about social and social-level phenomena.

12 Accounts of mechanisms may also identify the realizing components of an entity and the activities they enable (see, e.g. Machamer et al., 2000). To make the discussion manageable, we focus exclusively on microfoundationalist accounts as descriptions of lower-level intervening causal chains of events.
} 
roughly, that the causal chain of events is centered round individuals. ${ }^{13}$ More precisely, an account of the underlying individual-level mechanisms is often taken to consist of three parts that are all individual-involving (see, e.g., Hedström \& Swedberg, 1996). The first outlines how a social phenomenon resulted in individuals forming various beliefs and desires and having certain action opportunities in their physical and/or social context of action. The second lays out how these beliefs, desires, and opportunities made individuals act and interact in a certain manner. The third states how these actions and interactions, intentionally or unintentionally, brought about a certain social phenomenon. Frequently, Coleman's famous boat model is used to illustrate this three-part account (Coleman, 1986, 1990). Accordingly, the move from one social-level phenomenon down to individual-level events and up again to another social-level phenomenon is shown depicting a boat form.

Before moving on, it is worth stressing why (5) constitutes a more inclusive notion of individualist explanations than (4): (5), but not (4), permits the description of social phenomena as playing an active (and not only a passive) causal role vis-à-vis individuals. As such, individualist explanations should include a specification of how social phenomena had an effect on individuals. It is only purely holist explanations where both the explanans and the explanandum refer to a social-level phenomenon without individualist mechanisms that the individualist opposes.

The microfoundationalist position is widespread. Jon Elster and Daniel Little, among others, have defended it in the context of Marxist social theorizing (Elster, 1983, 1985, 1989; Little, 1986, 1991). Moreover, as Tuukka Kaidesoja observes, many proponents of analytical sociology, a currently influential school of social theorizing, endorse the position (Kaidesoja, 2013: p. 306). Examples include Demeleunare (2011), Hedström (2005), and Hedström and Bearman (2009). Microfoundationalists are opposed by methodological holists who contend that purely holist explanations may sometimes stand on their own: they do not always need to be supplemented by an individualist explanation.

On this basis, let's return to the question of whether ABM-based explanations are necessarily individualist in the broad microfoundationalist sense. The answer is no and the reason is that ABM-based explanations may be purely holist ones, that is, ones in which both the explanans and explanandum denote a social phenomenon. As noted in the previous section, the basic agents in an ABM may be interpreted as social entities. Consequently, an explanation may also state how the actions of social entities gave rise to some social phenomena. This is, for example, illustrated by Cederman's ABM of the way in which the behavior of democratic states give rise to the development of zones of peacefully co-existing democracies (Cederman, 2001) or by standard ABMs in macroeconomics that are entirely in terms of social entities or aggregates (surveyed by Di Guilmi, 2018). Evidently, an ABM-based explanation along these lines may be offered on its own, that is, as a self-standing explanation even though it is not accompanied by a microfoundational account that spells out how individuals were implicated in this process. Nothing about the nature of ABM models forces their explanations to mention any individual human agents. Additionally, nothing

\footnotetext{
13 For our purposes, it is not necessary to go into the difficult and controversial issue of how exactly to distinguish individual or lower levels from social or higher levels. For a discussion of this issue, see, e.g. Zahle (2019).
} 
about them prevents models that do include individual agents as causal factors from also including social factors that causally interact and thus which base purely social explanations, which (5) precludes.

The final notion of individualist explanations we examine differs from (5) by adding that microfoundational accounts may cite mechanisms that also revolve around social entities at a lower level (at a smaller scale) than the social phenomena described in a purely holist explanation (this notion is defended by, e.g., Coleman, 1990: p. 5). Sometimes the lower-level social entities are described as quasi-individuals, the idea being that they may be regarded (or treated) as agents who act in light of their reasons. In our view, the only way to lend some plausibility to the claim that these explanations are individualist despite the fact that the mechanisms do not have to be at the individual level is to see the lower-level social entities as being individual-like in that they are somehow agents too. Otherwise, the position loses completely touch with the core meaning of methodological individualism which is that social explanations should be in terms of individuals. This clarified, the conception may be summarized as follows:

(6) Individualist explanations are ones that describe only individuals, their nonrelational properties, their relations to their physical environment that is their context of action, their relation to other individuals, their relations to their social environment that is their context of action, and the social phenomena that causally influence them. These descriptions are part of specifying the underlying individual-level mechanisms that link social phenomena. Alternatively, individualist accounts may describe lower-level social entities, their nonrelational properties, their relations to their physical environment that is their context of action, and the higher-level social phenomena that causally influence them. These descriptions are part of a specification of the mechanisms, involving lowerlevel social entities, that link higher-level social phenomena.

In contrast to (5), (6) introduces a distinction between higher- and lower-level social phenomena in the last part of the definition. By implication, it goes hand-inhand with a slightly expanded conception of purely holist explanations: these should either be identified with explanations in which both the explanans and explanandum describe social phenomena (when mechanisms are individual-level) or with ones in which the explanans and explanandum refer to higher-level social phenomena (when mechanisms are lower-level social ones). In other words, we have the possibility of social entities at two levels with holist explanations at either; the reductionist force of individualism becomes providing lower-level social grounds for social explanations at a more macrolevel. For example, microfoundations for macroeconomics might involve relations between a government and other higher-level factors such as interest rates whose microfoundations are in the behavior of banks, firms and households treated as maximizing individuals.

As weak a notion of individualist explanations as (6) is, it should be transparent that $\mathrm{ABM}$ explanations still do not have to meet this requirement for several reasons, both of which we have seen earlier. First, ABM-models are compatible with offering self-standing explanations of how one higher-level social entity causally influenced another higher-level social entity. Too see this, return to Cederman's ABM of the way in which the behavior of basic agents in the form of democratic states give 
rise to the development of zones of peacefully co-existing democracies (Cederman, 2001). Evidently, an ABM-based explanation along these lines may be offered as a self-standing explanation of how the behavior of basic agents that are higher-level entities (democracies) generated another higher-level entity (zones of peacefully coexisting democracies). It is perfectly possible not to supplement this explanation with a microfoundational account that revolves around lower-level social entities (and/or individuals). Many similar examples can be found in ABMs in macroeconomics (e.g. Di Guilmi, 2018).

Second as we saw in considering (4), ABMs can allow for causal interaction of entities and properties in the environment, including the social environment, of basic agents. The same considerations also show why ABM-based explanations in (6) need not be individualist either. Consider an ABM-model of individual human beings who act in an environment that includes social entities like government entities influencing other social entities like banks, or larger social entities like banks influencing more "micro" but social entities like household depositers. There are an enormous number of such models of financial behavior involving individuals and collective entities that are widely used in the academic and policy literature (see, for example, the surveys of Robertson (2003) and Chan-Lau (2017)). Based on such a model, explanations are provided which detail how the social entities in the environment influence each other and present them as self-standing explanations (i.e. without any accompanying account of the underlying individual-level and/or lower social-level mechanisms) and as a result ABM-based explanations are not necessarily individualist from the perspective of (6), the most inclusive notion of individualist explanations in the microfoundational sense. More generally, this means that explanations based on ABMs are not inevitably individualist whether in the classic or microfoundational sense.

With (6), we have now worked through all possible variants of MI that our schema allows and shown that ABMs need not satisfy even the weakest of them. One last remaining way to challenge this conclusion is by proposing an understanding of individualist explanations that we have not considered and then arguing that ABM-based explanations are inevitably individualist in this other sense-a prospect raised by Manzo against the sort of approach we adopt (Manzo, 2020).

Finding such alternatives faces the problem that we have considered a very wide range of notions of individualist explanations: proposed versions are likely not to make a difference to the conclusion we arrive at, or to be only individualist in name and stipulative definitions that make the debate empty. Manzo, for example, proposes that individualist explanations should be defined without placing any restrictions on the sort of entities that they may mention (see, e.g., ibid.213). By implication, individualist explanations are not necessarily in terms of individuals. For this reason, we think that this conception, though interesting, is no longer recognizably individualist. Moreover, Manzo suggests general explanatory properties that both MI explanations and ABMs share, but that comparison requires one to delineate what is meant by "individualist explanation" and then to show that ABMs and individualist explanations share those properties. We do not believe this strategy can circumvent the kind of version-byversion type arguments we have provided here. 


\section{Conclusion}

ABMs are an important social research tool. In this paper, we have examined whether ABM-based explanations in the social sciences are inevitably methodologically individualist. To this end, we first offered an introduction to ABMs and individualist explanations, while stressing that they both admit of multiple interpretations. Next, we further cashed out the MI program in terms of six notions of individualist explanations running from the most purely individualist to the most socially promiscuous. More precisely, claims 1)-4) are increasingly inclusive formulations of individualist explanations according to classic MI, whereas thesis (5)-(6) are even broader conceptions of individualist explanations espoused by microfoundationalists. In connection with each, we showed that ABM-based explanations need not be individualist.

This finding still leaves it open to MIs to claim that though explanations based on ABMs are not inevitably individualist, they nonetheless should be so. That is, the classic MI proponent, who maintains that only individualist explanations should be offered, may obviously insist that ABM-based explanations should be individualist, even though they may be holist. Similarly, the microfoundationalist who holds that purely holist explanations should always be supplemented by individualist explanations (microfoundational accounts) may submit that though it is possible to use ABMs as basis for purely holist explanations, the latter should always be supplemented with microfoundational accounts. Though we have not considered this line of individualist argument in this paper, we would like, in closing, to make the following brief observations: It goes without saying that these claims, viz. that ABM explanations should be individualist, are in need of justification. Several theorists have argued that the reasons MIs have offered in support of both the classic and microfoundational MI program must be found wanting (e.g. Conte et al., 2001: p. 189ff; Kincaid, 1996, 1997; Ross, 2005, 2014; Sawyer, 2005; Weber \& Van Bouvel, 2002; Zahle, 2016; Zahle \& Kincaid, 2019). We believe that these arguments carry over to attempts to promote MI when offering ABM-based explanations: the reasons in support of MI in an ABM context do not differ from those in support of MI in any context. Accordingly, we believe not only that $\mathrm{ABM}$ explanations do not necessarily implement the individualist program, but also that they shouldn't always do so, though that is an argument for another time. ${ }^{14}$

Funding Open access funding provided by University of Bergen (incl Haukeland University Hospital).

Open Access This article is licensed under a Creative Commons Attribution 4.0 International License, which permits use, sharing, adaptation, distribution and reproduction in any medium or format, as long as you give appropriate credit to the original author(s) and the source, provide a link to the Creative Commons licence, and indicate if changes were made. The images or other third party material in this article are included in the article's Creative Commons licence, unless indicated otherwise in a credit line to the material. If material is not included in the article's Creative Commons licence and your intended use is not permitted by statutory regulation or exceeds the permitted use, you will need to obtain permission directly from the copyright holder. To view a copy of this licence, visit http://creativecommons.org/licenses/ by/4.0/.

14 We would like to thank the anonymous reviewers for their helpful suggestions. 


\section{References}

Agassi, J. (1960). Methodological individualism. British Journal of Sociology, 11, 244-270.

Agassi, J. (1975). Institutional individualism. British Journal of Sociology, 26, 144-155.

Agha, G. (1987). Actors: A model of concurrent computation in distributed systems. MIT Press.

Becker, G. (1976). The economic approach to human behavior. University of Chicago Press.

Bedau, M. (1997). Weak emergence. Nous, 31(S11), 375-399.

Billari, F., \& Praskawetz, A. (Eds.). (2003). Agent-based computational demography. Springer.

Cederman, L.-E. (2001). Modeling the democratic peace as a Kantian selection process. The Journal of Conflict Resolution, 45(4), 470-502.

Chan-Lau, J. (2017). ABBA: An agent-based model of the banking system. IMF working paper.

Coleman, J. S. (1986). Social theory, social research, and a theory of action. American Journal of Sociology, 91(6), 1309-1335.

Coleman, J. S. (1990). Foundations of social theory. The Belknap Press of Harvard University Press.

Conte, R., Edmonds, B., Moss, S., \& Swayer, R. K. (2001). Sociology and social theory in agent based social simulation: A symposium. Computational and Mathematical Organization Theory., 7(3), 183-205.

Demeulenaere, P. (2011). Introduction. In P. Demeulenaere (Ed.), Analytical sociology and social mechanisms (pp. 1-30). Cambridge University Press.

Di Guilmi, C. (2018). The agent-based approach to post-keynesian macro-modelling. In R. Veneziani \& L. Zamparelli (Eds.), Analytic political economy. Wiley.

Di Lorio, F., \& Chen, S.-H. (2019). On the connection between agent-based simulation and methodological individualism. Social Science Information, 58(2), 354-376.

Elder-Vass, D. (2010). The causal power of social structures, emergence. Structure and agency. Cambridge University Press.

Elster, J. (1983). Explaining technical change. A case study in the philosophy of science. Cambridge University Press.

Elster, J. (1985). Making sense of Marx. Cambridge University Press.

Elster, J. (1989). Nuts and bolts for the social sciences. Cambridge University Press.

Epstein, B. (2015). The ant trap. Rebuilding the foundations of the social sciences. Oxford University Press.

Epstein, J. (2006). Generative social science. Cambridge University Press.

Epstein, J., \& Axtell, R. (1996). Growing artificial societies. MIT Press.

Gallegati, A., Palestrini, A., \& Russo, A. (2017). Introduction to agent-based economics. Academic Press. Hamill, K., \& Gilbert, N. (2016). Agent-based modeling in economics. Wiley.

Hedström, P. (2005). Dissecting the social. Cambridge University Press.

Hedström, P., \& Bearman, P. (2009). What is analytical sociology all about? An introductory essay. In P. Hedström \& P. Bearman (Eds.), The Oxford handbook of analytical sociology (pp. 2-24). Oxford University Press.

Hedström, P., \& Swedberg, R. (1996). Social mechanisms. Acta Sociologica, 39(3), 281-308.

Hedström, P., Swedberg, R., \& Udehn, R. (1998). Popper's situational analysis and contemporary sociology. Philosophy of the Social Sciences, 28(3), 339-364.

Hegselmann, R. (2017). Thomas C. Schelling and James M. Sakoda: The intellectual, technical, and social history of a model. Journal of Artificial Societies and Social Simulation, 20(3), 15-27.

Hesse, M. (1966). Models and analogies in science. Notre Dame University Press.

Hodgson, G. M. (2007). Meanings of methodological individualism. Journal of Economic Methodology, 14(2), 211-226.

Holland, J. (1975). Adaptation in natural and artificial systems. MIT Press.

Homans, G. (1974). Human behavior: Its elemenatry forms. Harcourt Brace.

Jarvie, I. C. (1972). Concepts and society. Routledge and Kegan Paul.

Jarvie, I. C. (1998). Situational logic and its reception. Philosophy of the Social Sciences, 28(3), 365-380.

Jennings, N., Sycara, K., \& Wooldridge, M. (1998). A roadmap of agent research and development. Autonomous Agents and Multi-Agent Systems, 1(1), 7-38.

Kaidesoja, T. (2013). Overcoming the biases in microfoundationalism: Social mechanisms and collective agents. Philosophy of the Social Sciences, 43(3), 301-322.

Kincaid, H. (1996). Philosophical foundations of the social sciences. Cambridge University Press.

Kincaid, H. (1997). Individualism and the unity of science. Rowman and Littlefield.

Kincaid, H. (2015). Open empirical and methodological issues in the individualism-holism debate. Philosophy of Science, 82, 1127-1138. 
Kincaid, H. (2020). Concrete ontology. Philosophy of the Social Sciences. https://doi.org/10.1177/ 0048393120925797

Kirman, A. P., \& Vriend, N. J. (2001). Evolving market stricture: An ACE model of price dispersion and loyalty. Journal of Economic Dynamics and Control, 25, 459-502.

Kohler, T., \& Gumerman, G. (2000). Dynamics in human and primate societies: Agent based modeling of social and spatial processes. Oxford University Press.

Langdon, C. (1989). Artificial life: Proceedings of an interdisciplinary workshop on the synthesis and simulation of living systems. Addison-Wesley.

Laver, M., \& Sergenti, E. (2012). Party competition: An agent-based model. Princeton NJ: Princeton University Press.

Little, D. (1986). The scientific marx. University of Minnesota Press.

Little, D. (1991). Varieties of social explanation. Westview Press.

Lukes, S. (1968). Methodological individualism reconsidered. The British Journal of Sociology, 19(2), 119-129.

Machamer, P. K., Darden, L., \& Craver, C. F. (2000). Thinking about mechanisms. Philosophy of Science, $67,1-25$.

Macy, M., \& Flache, A. (2009). Social dynamics from the bottom up. Agent-based models of social interaction. In P. Hedström \& P. Bearman (Eds.), The Oxford handbook of analytical sociology (pp. 245-269). Oxford University Press.

Manzo, G. (2020). Agent-based models and methodological individualism: Are they fundamentally linked? Revue L'année Sociologique, 70, 197-229.

Marchionni, C., \& Ylikoski, P. (2013). Generative explanation and individualism in agent-based simulation. Philosophy of the Social Sciences, 43(3), 323-340.

Morgan, M. (2012). The world in the model. Cambridge University Press.

Morgan, M., \& Morrison, M. (1999). Models as mediators. Cambridge University Press.

Namatame, A., \& Chen, S.-H. (2016). Agent-based modeling and network dynamics. Oxford University Press.

O’Sullivan, D., \& Haklay, M. (2000). Agent-based models and individualism: Is the world agent-based? Environment and Planning a: Economy and Space, 32(8), 1409-1425.

Pooley, R. (1987). An introduction to programming in simula. Alfred Waller Ltd.

Popper, K. R. (1996). The myth of the framework. In Defense of science and rationality. Routledge.

Robertson, D. (2003). Agent-based models of a banking network as an example of a turbulent environment: The deliberate vs. emergent strategy debate revisited. Emergence, 5(2), 56-71.

Ross, D. (2005). Economic theory and cognitive science. MIT Press.

Ross, D. (2014). Philosophy of economics. Macmillan Palgrave.

Sakoda, J. M. (1971). The checkerboard model of social interaction. Journal of Mathematical Sociology, l(1), 119-132.

Salaman, T. (2011). Design of agent-based models. Academic Series.

Sawyer, K. (2005). Social emergence. Cambridge University Press.

Sawyer, R. K. (2004). The mechanisms of emergence. Philosophy of the Social Sciences, 34(2), 260-282.

Schelling, T. C. (1971). Dynamic models of segregation. Journal of Mathematical Sociology, 1(2), 143-186.

Sober, E. (1988). Reconstructing the past: Parsimony, evolution and inference. MIT Press.

Squazzoni, F. (2000). Agent-based computational sociology. Wiley.

Uchmanski, J., \& Grimm, V. (1996). Individual-based modelling in ecology: What makes the difference? Trends in Ecology and Evolution, 11(10), 20091-20096.

Udehn, L. (2001). Methodological individualism. Background, history, and meaning. Routledge.

Udehn, L. (2002). The changing face of methodological individualism. Annual Review of Sociology, 28, 479-507.

Wan, P.Y.-Z. (2011). Emergence à la systems theory: epistemological Totalausschluss or ontological novelty? Philosophy of the Social Sciences, 41(2), 178-210.

Watkins, J. W. N. (1952). Ideal types and historical explanation. The British Journal for the Philosophy of Science, 3(9), 22-43.

Watkins, J. W. N. (1957). Historical explanation in the social sciences. The British Journal for the Philosophy of Science, 8(30), 104-117.

Weber, E., \& Van Bouwel, J. (2002). Can we dispense with structural explanations of social facts? Economics and Philosophy, 18, 259-275. 
Zahle, J. (2016). Methodological holism in the social sciences. In Zalta, E. N. (Ed.), Stanford encyclopedia of philosophy (pp. 1-39). http://plato.stanford.edu/.

Zahle, J. (2019). Limits to levels in the methodological individualism-holism debate. Synthese. https://doi. org/10.1007/s11229-019-02469-2

Zahle, J., \& Kincaid, H. (2019). Why be a methodological individualist? Synthese, 196(2), 655-675.

Zahle, J., \& Kincaid, H. (2020). Agent-based modelling with and without methodological individualism. In H. Verhagen, M. Borit, G. Bravo, \& N. Wijermans (Eds.), Advances in social simulation-looking in the mirror (pp. 15-25). Springer.

Publisher's Note Springer Nature remains neutral with regard to jurisdictional claims in published maps and institutional affiliations. 